\title{
Avaliação multicritério da gestão colaborativa de grupos musicais
}

\section{independentes}

\author{
Multicriteria evaluation of collaborative management of independent musical groups \\ Evaluación multicriterio de la gestión colaborativa de grupos musicales independientes
}

Received: 10/11/2021 | Reviewed: 10/18/2021 | Accept: 10/19/2021| Published: 10/21/2021

\author{
Aldery Silveira Junior \\ ORCID: https://orcid.org/0000-0002-7852-9460 \\ Universidade de Brasília, Brasil \\ E-mail: aldery@unb.br \\ Marcus Vinícius de Oliveira Sousa \\ ORCID: https://orcid.org/0000-0003-4624-2411 \\ Universidade de Brasília, Brasil \\ E-mail: marcsousabrasil@gmail.com \\ Rafael Rabelo Nunes \\ ORCID: https://orcid.org/0000-0002-1538-4276 \\ Universidade de Brasília, Brasil \\ Centro Universitário Atenas, Brasil \\ E-mail: rafaelrabelo@unb.br
}

\begin{abstract}
Resumo
Grupos musicais independentes são aqueles que atuam de forma autônoma, sem grandes investimentos ou parcerias, e coordenando suas próprias ações. Nesse sentido, os membros desses grupos precisam desenvolver habilidades e praticar funções que vão além do universo musical, para assim manterem um bom desempenho e alcançarem suas metas. $\mathrm{O}$ presente estudo teve como objetivo avaliar a gestão colaborativa de grupos musicais independentes. Para tanto, utilizouse da metodologia Multicritério de Apoio à Decisão (MCDA), realizou-se uma pesquisa de campo, na qual representantes de quarenta e dois grupos musicais de Brasília responderam a um questionário, avaliando a gestão de seus respectivos grupos, de acordo com os critérios estabelecidos no modelo de avaliação. A construção do modelo de avaliação constou de sete etapas: Definição do rótulo do problema, identificação dos atores envolvidos no processo de avaliação, determinação dos elementos de avaliação (critérios), definição dos descritores, construção das funções de valor, determinação das taxas de substituição e construção da árvore de valor. Os dados foram tratados pelo software Hiview3 e analisados com base no modelo de avaliação desenvolvido. As avaliações obtidas na pesquisa foram baixas, indicando a insatisfação dos representantes dos grupos musicais independentes de Brasília com a gestão colaborativa exercida em seus respectivos grupos e demonstrando a necessidade de implementação de melhorias em seus sistemas de gestão e de produção.
\end{abstract}

Palavras-chave: Gestão colaborativa; Metodologia multicritério de apoio à decisão; Grupos musicais independentes.

\begin{abstract}
Independent musical groups are those that act autonomously, without major investments or partnerships, and coordinating their own actions. In this sense, the members of these groups need to develop skills and practice functions that go beyond the musical universe, in order to maintain a good performance and reach their goals. The present study aimed to evaluate the collaborative management of independent musical groups. For this purpose, the Multicriteria Decision Support (MCDA) methodology was used, a field research was carried out, in which representatives of fortytwo musical groups from Brasília answered a questionnaire, evaluating the management of their respective groups, according to the criteria established in the evaluation model. The construction of the evaluation model consisted of seven steps: Definition of the problem label, identification of the actors involved in the evaluation process, determination of evaluation elements (criteria), definition of descriptors, construction of value functions, determination of replacement rates and construction of the value tree. Data were processed by Hiview3 software and analyzed based on the developed evaluation model. The ratings obtained in the survey were low, indicating the dissatisfaction of representatives of independent musical groups in Brasilia with the collaborative management exercised in their respective groups and demonstrating the need to implement improvements in their management and production systems. Keywords: Collaborative management; Multicriteria decision aid methodology; Independent musical groups.
\end{abstract}




\section{Resumen}

Los grupos musicales independientes son aquellos que actúan de forma autónoma, sin grandes inversiones ni alianzas, y coordinando sus propias acciones. En este sentido, los integrantes de estos grupos necesitan desarrollar habilidades y practicar funciones que van más allá del universo musical, con el fin de mantener una buena interpretación y alcanzar sus metas. El presente estudio tuvo como objetivo evaluar la gestión colaborativa de grupos musicales independientes. Para ello, se utilizó la metodologia Multicriteria Decision Aid (MCDA), se realizó una investigación de campo, en la cual representantes de cuarenta y dos grupos musicales de Brasilia respondieron un cuestionario, evaluando la gestión de sus respectivos grupos. De acuerdo con los criterios establecidos en el modelo de evaluación. La construcción del modelo de evaluación constó de siete pasos: Definición de la etiqueta del problema, identificación de los actores involucrados en el proceso de evaluación, determinación de elementos de evaluación (criterios), definición de descriptores, construcción de funciones de valor, determinación de tasas de reemplazo y construcción del árbol de valor. Los datos fueron procesados por el software Hiview3 y analizados en base al modelo de evaluación desarrollado. Las calificaciones obtenidas en la encuesta fueron bajas, lo que indica el descontento de los representantes de los grupos musicales independientes en Brasilia con la gestión colaborativa que ejercen en sus respectivos grupos y demuestra la necesidad de implementar mejoras en sus sistemas de gestión y producción.

Palabras clave: Gestión colaborativa; Metodología de apoyo a la decisión de criterios múltiples; Grupos musicales independientes.

\section{Introdução}

O Brasil possui uma enorme riqueza artística e cultural, reconhecida por seus encantos e por sua diversidade. Dentre os principais segmentos que caracterizam essa riqueza, a indústria fonográfica tem ganhado grande destaque ao longo do tempo, dentro e fora do país. Esse crescimento ganhou força, principalmente, a partir da segunda metade do século XX, com o surgimento da televisão e após a fusão de gêneros musicais que deram origem à música popular brasileira (Saldanha, 2013). A partir de então, essa indústria sofreu grandes mudanças, sendo afetada por uma série fenômenos industriais e sociais que transformaram as relações de produção e consumo da matéria musical (Vicente \& De Marchi, 2014).

Tais transformações, que estão ligadas aos avanços nas tecnologias da informação e da comunicação, contribuíram para que a indústria da música passasse por alguns períodos de reestruturação e de adaptação ao mercado. Além disso, considerando a queda no desempenho das grandes gravadoras - as quais detinham o maior poder sobre o lançamento de novos artistas - houve uma expansão da produção independente, acompanhando a tendência de desverticalização dos processos que envolvem a produção musical.

Com a facilidade de acesso à novas tecnologias, criaram-se categorias de agentes e produtores artísticos e culturais, que atuam de maneira mais estratégica junto a parcerias pontuais, encurtando distâncias e promovendo novos métodos de execução, gravação e apresentação de conteúdo midiático. Por outro lado, alguns artistas optam por percorrer esse caminho de forma mais solitária, seja pelas condições que lhes são impostas no contexto em que vivem ou pela preferência de encarar o processo de uma forma mais personalizada e de baixo custo.

Nesse contexto, os artistas que encaram a independência de grandes agentes precisam munir-se de habilidades para desenvolverem seus projetos, o que requer uma capacitação em diferentes áreas de atuação - assim como a do empreendedorismo e da gestão. Portanto, partindo do pressuposto que deverão comportar-se como uma pequena organização, esses artistas devem ser capazes de controlar e coordenar suas próprias atividades dentro do cenário em que se inserem, para, então, conseguirem gerar resultados a curto, médio e longo prazo.

Nesta perspectiva, o estudo realizado concentrou-se em avaliar a gestão colaborativa de grupos musicais que atuam de forma independente, considerando as principais atividades por eles exercidas, desde a criação de conteúdo até a sua comercialização. Para essa avaliação, utilizou-se a metodologia multicritério de apoio à decisão (MCDA), que, a partir de uma pesquisa de campo realizada junto à alguns grupos musicais independentes da cidade de Brasília, objetivou identificar a forma como esses grupos (ou bandas) são geridos e propor melhorias para os pontos críticos mapeados na avaliação. 
Salienta-se, por fim, que o mercado da música cresce de forma global e exponencial, movimentando a economia em diversos países pelo mundo. De acordo com a Federação Internacional da Indústria Fonográfica (IFPI), em seu relatório global de música gravada, publicado em 2019, a indústria registrou, no ano de 2018, um crescimento pelo quarto ano consecutivo, liderado por representantes da América Latina, em especial o Brasil, movimentando mais de 19 bilhões de dólares nesse período. O crescimento registrado foi de $9,7 \%$ em relação a 2017, a maior taxa desde que a IFPI começou a acompanhar o mercado, em 1997 (IFPI, 2019).

\section{Referencial Teórico}

Com a finalidade de prover um embasamento para os procedimentos realizados na pesquisa de campo, além de levantar o estado da arte em torno da temática escolhida, serão abordados os seguintes tópicos considerados relevantes para a compreensão da área de estudo: Gestão colaborativa, Desverticalização da produção, Produção de música independente e Metodologia multicritério de apoio à decisão.

\subsection{Gestão Colaborativa}

O conceito de colaboração é amplamente utilizado no contexto organizacional da atualidade, assim como em diversas outras áreas do conhecimento e de atuação profissional. Estudos recentes sobre práticas colaborativas têm se destacado, sobretudo, no contexto educacional (Búrigo et al., 2016; Barbosa \& Serrano, 2005; Almeida, 2005), e de cadeia de suprimentos (Antunes, 2012; Min et al., 2005; Siqueira et al., 2015; Gomes \& Neto, 2015; Rodrigues \& Sellito, 2008; Vitorino Filho et al., 2016).

A palavra colaborar originou-se do termo em latim collaborare, que significa trabalhar com ou trabalhar em conjunto com outrem. Dessa forma, e a partir de um panorama construído com base nos estudos citados acima, a respeito das práticas colaborativas nas organizações, entende-se que o conceito de colaboração gira em torno de alguns pontos norteadores, como: coletividade, reciprocidade, compartilhamento de informações, trabalho em equipe, integração de processos, entre outros.

Martinho (2018) defende que colaboração tem mais a ver com a experiência de um conjunto de pessoas que, por via de um processo de interação múltipla, se unem em um ambiente desafiador e de apoio mútuo. Em adição à essa ideia, CamarinhaMatos et al. (2009) destacam o envolvimento e a confiança mútua entre os participantes para a resolução de um problema em conjunto, o que requer tempo, esforço e dedicação.

A interação e a colaboração são aspectos essenciais para a criação e manutenção de relacionamentos propícios para o desenvolvimento de projetos em harmonia. Essa noção está sujeita ao reconhecimento de que o trabalho conjunto é importante para a comunidade (Burgos \& Mertens, 2016). Nessa lógica, a constituição de uma unidade de trabalho dinâmica exige a convivência com as ambiguidades e os conflitos de interesses presentes nos relacionamentos, de forma a convergir para o benefício do grupo (Almeida, 2005).

Alguns autores salientam a porosidade da fronteira entre colaboração e outros termos usados de forma semelhante, como cooperação e competição. Camarinha-Matos et al. (2009) apontam que a cooperação é um elemento intrínseco às práticas colaborativas, referindo-se à divisão de trabalho entre equipes e atuação de forma quase independente, mesmo que com objetivos compatíveis. Já a colaboração é um processo com maior grau de integração entre as partes em prol de um objetivo em comum e da geração de valor mútua.

Por outro ângulo, ao seguir a lógica de Jean Piaget, envolvendo suas fundamentações psicológicas e epistemológicas aplicadas à pedagogia, Cogo (2006) afirma que colaboração diz respeito à troca de informações e à discussão entre pessoas em 
um processo de aprendizagem que ocorre previamente à cooperação. Por outro lado, a cooperação retrata uma interação mais voltada à operação racional e construção do conhecimento entre os indivíduos.

Associadamente, alguns autores incluem a relação entre competição e colaboração na discussão abordada acima, atribuindo um distanciamento entre os termos: na competição, para que uma parte ganhe é preciso que a outra perca. Já na colaboração, o ganho de uma não exclui o de outra (Rodrigues \& Sellito, 2007).

Apesar da diferenciação dos termos citados ser uma preocupação por parte de diversos autores, o presente estudo não fará a discriminação deles. Desse modo, e considerando a carência de pesquisas voltadas para o uso desses conceitos na Administração, opta-se aqui, por utilizar o termo colaboração, no sentido mais amplo da palavra, apoiando-se nas abordagens de Camarinha-Matos et al. (2009) e de Martinho (2018).

Nesse diapasão, a essência da Gestão Colaborativa baseia-se no interesse coletivo em detrimento do interesse individual, onde uma estrutura organizacional promove ações em conjunto e de forma inclusiva, com o fim de coordenar diferentes pontos de vista (Búrigo et al., 2016). Com essa prática, cria-se um ambiente de maior interatividade e proximidade entre as pessoas, cujo relacionamento pode propiciar inúmeros benefícios, assim como uma melhor integração de competências, tecnologias e materiais de apoio, além do desenvolvimento de processos com participação mais ativa das equipes visando o alcance de objetivos em comum (Almeida, 2005).

Por meio de uma gestão compartilhada, o planejamento e o desenvolvimento de atividades podem ser realizados por um conjunto de pessoas com igual autoridade, impulsionando a confiança nos processos decisórios (Búrigo et al., 2016). Com a atuação dos gestores respaldada por participações colaborativas, criam-se redes de aprendizagem entre os participantes capazes de suportar conflitos e divergências (Aquino, 2015). Essas redes servem, ainda, como espaço para o reconhecimento de limitações e potencialidades, assegurando o diálogo, a negociação, e a busca do entendimento coletivo (Almeida, 2005).

Em uma pesquisa realizada com o fim de traçar um perfil das práticas colaborativas nas empresas, Min et al. (2005) apontam duas principais vertentes para a compreensão de colaboração: a primeira diz respeito à colaboração como um processo de negociação entre empresas, no qual membros de diferentes organizações trabalham com fim de tomarem decisões e resolverem problemas em conjunto, obtendo maiores benefícios do que se estivessem atuando de forma isolada; já a segunda, é retratada como uma ligação entre as partes, na qual os agentes envolvidos compartilham informações e recursos em prol de um objetivo mútuo, integrando atividades e criando interdependência funcional em busca de melhores resultados.

Em um estudo voltado à colaboração dentro da gestão de cadeias de suprimento, Gomes e Neto (2015, p. 565) apontam que esse processo: “[...] geralmente ocorre quando há a troca de informações e tecnologias entre duas ou mais empresas, as quais dividem a responsabilidade do planejamento, gestão, execução e acompanhamento do desempenho". Partindo desse pressuposto, infere-se que a gestão colaborativa ocorre quando as partes interessadas trabalham para alcançar maior eficácia, planejando e executando operações de forma conjunta (Vitorino Filho et al., 2016).

Ao longo das últimas décadas, foi possível observar uma forte tendência voltada à arranjos organizacionais menos fragmentados ou hierarquizados nas empresas, rompendo com o paradigma fordista (Búrigo et al., 2016). Com o aumento no número de estruturas mais informais na atualidade, o trabalho colaborativo adquire maior relevância, especialmente como uma ferramenta para sobreviver à crescente competição entre empresas e mercados (Gomes \& Kliemann Neto, 2015; CamarinhaMatos et al., 2009).

As práticas colaborativas são encaradas como sendo vitais para o desenvolvimento de capacidades nas empresas, assim como para obter melhor desempenho frente aos fenômenos de mercado (min et al., 2005). Ao implementar ações colaborativas eu seus processos, as organizações assumem sistemas mais abertos de produção, reduzindo as fronteiras de atuação e fortalecendo a confiança e a sinergia entre parceiros de negócio (Rodrigues \& Sellito, 2007). 
Com sistemas mais flexíveis, há maior circulação de conhecimento e experiências entre os componentes de uma rede, estimulando um processo de retroalimentação da própria rede e de seus integrantes. Essas dinâmicas dentro das organizações concedem um caráter pedagógico às práticas colaborativas, pois as pessoas precisam aprender umas com as outras para agir em conjunto (Aquino, 2015, p. 5). Com isso em mente, a autora ressalta que:

[...] Co-laborar é inventar, a cada momento, formas de "fazer com" o outro. No "fazer com" não há distâncias ou isenção, mas sobretudo a mobilização de dimensões afetivas e hápticas em um encontro que pressupõe reconhecimento e valorização mútua. A colaboração é fundamentalmente marcada pela reciprocidade ou mutualismo. Constituem, portanto, práticas dialógicas e nãohierárquicas, que não podem ser dissociadas de uma atitude crítica e política de reconhecimento das relações de produção, e da reinvenção destas em condições concretas de construção e circulação horizontais de conhecimentos (Aquino, 2015, p. 5).

Por fim, essas práticas ainda são insipientes nas empresas, possuindo traços das organizações tradicionais, que focam na relação fornecedor-cliente ao invés de promover a devida integração entre parceiros de trabalho para melhorar a cadeia como um todo (Min et al., 2005; Siqueira et al., 2015). Os sistemas atuais de integração e colaboração ainda precisam de melhorias, e existem oportunidades de aprofundamento em seus estudos, em diversas áreas do conhecimento (Rodrigues \& Sellito, 2007; Siqueira et al., 2015; Gomes \& Neto, 2015).

\subsection{Desverticalização da Produção}

A produção de forma integrada (ou produção verticalizada), onde uma organização se encarrega de todas as etapas de produção, do nível operacional até o nível mais estratégico, era uma característica inerente às grandes empresas até o início do século XXI (Almeida \& Moura, 2005). Até então, as grandes indústrias se beneficiavam do trabalho em massa, seguindo o modelo Fordista de produção, cujo foco era produzir em grande escala através da mão de obra barata e da divisão de trabalho (Costa, 2017). No geral, as tarefas eram tão simples e padronizadas que não exigiam especialização alguma, possibilitando a contratação de inúmeros trabalhadores sem qualificações, de imigrantes em situação difícil, e até de crianças (Romero, 2004).

Após a virada do século, houve uma crescente tendência direcionada à quebra desse paradigma, principalmente devido à fatores como as mudanças no hábito de consumo, e os avanços científicos e tecnológicos aplicados às diferentes áreas de atuação industrial. Em vista disso, houve um crescente desinteresse em produtos padronizados, assim como o desenvolvimento de nichos específicos para determinados produtos que satisfazem as necessidades específicas dos consumidores (Romero, 2004).

Considera-se um marco da redução da cadeia de atividades e de processos (ou desintegração vertical), em diferentes níveis organizacionais, o surgimento do modelo de produção enxuta. Esse modelo foi introduzido pelos japoneses na economia pós-guerra como uma das soluções aos problemas financeiros da indústria. Com algumas diferenças históricas e sociais com relação às empresas do ocidente, a Toyota Motor Company, por exemplo, se deparou com algumas barreiras ao tentar ingressar no mercado automobilístico de grande escala, assim como a limitação do mercado interno e a grande concorrência do mercado externo (Amato Neto, 1994).

Com isso, o modelo de produção dessa e de outras grandes companhias passou a seguir uma filosofia mais coletivista e colaborativa, baseada na confiança múltipla entre fornecedores e em contratos a longo prazo (Amato Neto, 1994). Esse tipo de relacionamento promovia uma crescente integração entre os produtores e seus respectivos projetos.

A Toyota construiu uma relação de maior proximidade junto a seus fornecedores, garantindo sua independência e estabilidade econômico-financeira. Isso permitiu com que a empresa focasse em uma única atividade fim, descentralizando os processos intrínsecos à cadeia de produção de automóveis, sem comprometer o controle e a qualidade dos produtos (Amato Neto, 1995). Assim, foi apenas questão de tempo para que esse modelo de produção viesse a ser notado no ocidente, influenciando novas tendências de mercado, voltadas à modelos de gestão horizontais e mais flexíveis (Romero, 2004).

Entre outras consequências, essas mudanças possibilitaram uma melhora na dinâmica de relacionamentos entre empresas e fornecedores, que passaram a ter mais opções no mercado e mais independência financeira e estratégica, focando em 
áreas mais especializadas de atuação. Esse movimento também trouxe uma maior variedade para o mercado, incentivando novos produtores e valorizando iniciativas de pequenas organizações (Nakano, 2010).

Com essas transformações cada vez mais evidentes na indústria, as empresas começaram a praticar a segmentação de mercado, com foco em capacidades específicas, e externalizando parte de suas operações produtivas para fornecedores especializados (Fleury, 2003; Almeida \& Moura, 2005). Isso impulsionou a diminuição das escalas de produção e dos investimentos, dando maior abertura para que seus fornecedores pudessem explorar novos nichos do mercado e expandir seus negócios (Nakano, 2010).

Paralelamente, com um mercado cada vez mais competitivo, os sistemas verticalizados traziam como consequência um aumento na complexidade e um menor controle sobre a produção. Por tanto, como tentativa de solucionar essa fragmentação da cadeia, algumas empresas buscavam melhorar a coordenação de suas atividades por intermédio de um processo de cooperação e troca de informações (Fleury, 2003). Além disso, vale destacar que os avanços da informática e do setor de telecomunicações possibilitaram com que esse processo de coordenação fosse cada vez mais eficiente.

No Brasil, essa transição ganhou maior força a partir da década de 1990, onde a partir de um contexto de crise econômica e de políticas voltadas à flexibilização do mercado, a estabilidade das empresas dominantes era ameaçada por conta de suas capacitações limitadas, principalmente em relação à gestão de custos (Souza \& Lemos, 2016). Com isso, visando a melhoria administrativa, as empresas passaram a racionalizar suas atividades, terceirizando as menos essenciais e dando maior atenção à tomada de decisões (Costa, 2017). O processo de desverticalização nas indústrias brasileiras ainda se encontra em uma fase embrionária, carecendo de inovações e de maior integração entre empresas, funcionários e o Estado (Amato Neto, 1995).

A terceirização, ou externalização das atividades, ocorreu primeiro nas áreas de serviços gerais ou de apoio, como limpeza e segurança, por exemplo, visto que não comprometiam as atividades principais das empresas, mesmo que a relação com esses fornecedores não fosse de muita confiabilidade (Costa, 2017). Além disso, a instabilidade da mão de obra passou a ser uma preocupação, pois acarretava altos custos de investimento e não trazia segurança a longo prazo. Isso é visto como um problema presente até os dias de hoje no contexto industrial brasileiro.

Dentre os caminhos para a solução desse problema, Fleury (2003) destaca a importância da integração de processos e dos diversos participantes envolvidos na cadeia de produção e distribuição. Por meio da administração compartilhada, por exemplo, é possível interligar as unidades organizacionais e melhorar as relações internas e externas, solidificando a estrutura organizacional. Afinal, esse cuidado acaba gerando maior vantagem competitiva para que a empresa alcance seus objetivos (Amato Neto, 1995).

Com o passar dos anos, essa prática expandiu-se para diversas áreas da produção, chegando até a indústria criativa e cultural. Pois, com o mercado mais aberto para pequenos fornecedores, o acesso à novos métodos de produção aumentaram consideravelmente, possibilitando a experimentação e a customização de produtos e serviços. No âmbito fonográfico, por exemplo, a maior parte das grandes gravadoras passaram a sublocar alguns de seus serviços, como a gravação e a distribuição de material, visando otimizar seus lucros (De Marchi, 2008).

Desse modo, observou-se uma crescente tendência à flexibilização das relações entre artistas e produtores, descentralizando a estrutura gerencial dessas organizações, e incentivando, cada vez mais, as atividades baseadas na gestão colaborativa. Cabe ressaltar, por fim, que o desenvolvimento tecnológico é o maior fator de influência no processo de desverticalização do setor fonográfico (Nakano, 2010).

\subsection{Produção de Música Independente}

O conceito de música independente tem sua origem documentada nos Estados Unidos, a partir da primeira metade do Século XX, onde pequenos empreendimentos do setor fonográfico utilizavam-se de meios de produção mais autônomos para 
contemplar movimentos e gêneros musicais pouco aproveitados pelas grandes gravadoras (Galleta, 2014; Herschmann, 2010). Nessa época, alguns desses movimentos estavam associados, também, às lutas políticas negras e à contracultura no país. Em paralelo, o termo independente também surgia no cenário musical do Reino Unido, caracterizado pelo movimento punk emergente na década de 1970, e consolidado por pequenas empresas que viabilizavam a produção e distribuição desse tipo de música, independente de negócios com grandes gravadoras ou selos musicais.

No contexto brasileiro, o termo independente também ganha força a partir da década de 1970, para designar produções fonográficas com níveis diversos de autonomia, assim como ocorreu em grande parte do mundo (Galleta, 2014; Herschmann, 2010). No entanto, o termo se popularizou em torno de debates envolvendo o seu significado, que era atribuído, não só à forma de produção musical, mas também às características criativas supostamente comuns entre representantes desse meio. Como indicado no estudo de Galleta (2014, p. 69):

[...] no Brasil, o eixo principal desta identidade tem apontado historicamente para produções mais voltadas a públicos segmentados e de nicho, que buscam na alternativa de produção independente condições mais favoráveis à afirmação de propostas musicais diferenciadas em relação aos conteúdos e linguagens privilegiadas mais comumente nos meios mainstream; tratam-se ainda, neste caso, de produções tendencialmente menos afeitas ao alcance de públicos mais massivos (Galleta, 2014, p. 69).

Assim como as entidades envolvidas na produção musical - como é o exemplo de produtoras, gravadoras, selos, entre outros - músicos e bandas também passaram a operar mais livremente ao longo do tempo, como pequenas organizações, geridas por um único indivíduo ou grupo, geralmente sem grandes investimentos, e coordenando suas próprias atividades (De Marchi, 2008; Galleta, 2014; Herschmann, 2010). Tal fenômeno transcorreu por um conjunto de motivações, principalmente como efeito colateral do oligopólio construído por grandes empresas da indústria, conhecidas como majors, que ditavam o ritmo das produções, do lançamento de novos artistas e do mercado da música gravada (Nakano, 2010).

Entre outros fatores responsáveis pelo crescimento do interesse sobre as atividades independentes na música, no âmbito nacional e internacional, estão: (1) a democratização do acesso à novas tecnologias; (2) a maior proximidade entre os artistas e o público, por meio de redes sociais, técnicas de download e plataformas de streaming (forma de distribuição e compartilhamento de conteúdo multimídia por meio de uma rede de internet); (3) o desenvolvimento de redes de compartilhamento de conteúdo e dinâmicas produtivas entre os agentes envolvidos no mundo da música; e (4) o desenvolvimento de políticas culturais e processos econômicos identificados nos últimos anos (Galleta, 2014).

Com o desenvolvimento da internet e da capacidade de transmissão de dados, ao longo dos anos 1990 e 2000, alguns processos de grande importância para o setor musical, como o de distribuição, também ganhou novos horizontes, principalmente a partir do momento em que a técnica de compactação de arquivos revolucionou o modo em que isso ocorrera (Galleta, 2014).

A criação do formato de mídia MPEG-1/2 Audio Layer (MP3), por exemplo, possibilitou a portabilidade da matéria musical em grande volume, sem suporte físico (Nakano, 2010). Dessa maneira, dispensavam-se objetos pesados ou que ocupassem muito espaço, proporcionando maior conveniência para as pessoas, pois trata-se de um formato de mídia que reduz em até $90 \%$ o tamanho em relação ao arquivo original, sem comprometer sua qualidade, cuja variação é imperceptível aos ouvidos humanos (Gomes, 2016). Essa mudança também deu início à um processo de queda na relevância de mídias antecessoras, como a do Disco Compacto (CD).

A partir de então, as produções musicais passaram a depender cada vez menos da fabricação de discos, podendo chegar ao consumidor final por meio da acessibilidade e conectividade à internet e aplicativos de reprodução de mídia. Isso ganhou mais destaque ainda após o lançamento de dispositivos eletrônicos reprodutores de MP3 e outros formatos de mídia, como o iPod, por exemplo, dispositivo da empresa americana Apple que se destacou no mercado por sua conveniência e portabilidade.

Com a disseminação de competências e conhecimentos técnicos de produção e distribuição da música ao longo do tempo, o mercado atraiu novos interessados, assim como fornecedores especializados, possibilitando a externalização de 
atividades e diminuindo os custos e os riscos inerentes ao processo (Nakano, 2010); especialmente considerando que muitos desses processos passaram a ocorrer a partir de computadores pessoais em pequenos estúdios.

Por conseguinte, pequenos produtores e até os próprios artistas passaram a produzir música dentro de casa, com uma qualidade aceitável para o mercado. Com isso, começaram a surgir inúmeras gravadoras e estúdios independentes, com muitos desses profissionais vindos do quadro das majors, com a intenção de criar seu próprio negócio (De Marchi, 2008; Vicente, 2006).

Com a facilidade de entrada no mercado da música, as gravadoras independentes enxergaram novas oportunidades, ao explorar novos conceitos de produção, gêneros emergentes, e nichos de mercado que eram ignorados pelas majors, dando maior visibilidade à novos estilos musicais e atraindo consumidores (Nakano, 2010). Além disso, grande parte dos artistas sentiam-se pressionados pelas novas políticas de produtividade impostas pelas gravadoras, baseadas em parâmetros internacionais, o que causava divergências criativas e distanciamento entre as partes (De Marchi, 2008).

A cena independente acaba desempenhando um papel de prospecção de novos mercados, funcionando também como um campo de formação e teste de novos artistas. O que se torna atrativo para os grandes selos, produtoras e gravadoras, pois dessa forma conseguem analisar os riscos e oportunidades que uma parceria pode oferecer (Dias Tosta, 2000; Vicente, 2006). Da mesma forma, agentes independentes tornaram-se capazes de revelarem bandas e artistas visando contratos posteriores com as majors (Herschmann, 2010).

No Brasil, apesar de grandes produtoras e selos musicais ainda dominarem boa parte do cenário musical, foi possível observar uma maior participação de agentes independentes nos últimos anos. Esse fenômeno ocorreu principalmente a partir da segunda metade dos anos 1990, quando surgiram novas gravadoras no mercado, dando forma à uma retomada nos esforços de revitalização da produção nacional (De Marchi, 2008).

Diante disso, diversas empresas passaram a agir como mediadoras entre as majors e as entidades independentes, e até como prestadoras de serviço para os artistas, atuando de forma mais estratégica e pontual. Sua participação ocorrera em diversas etapas da produção, como na gravação e distribuição, sem depender dos interesses das grandes gravadoras, e de forma mais participativa (De Marchi, 2008; Nakano, 2010).

Por outro lado, considerando a complexidade e a quantidade de fatores que envolvem o exercício da atividade musical, é comum que os artistas, quando desvinculados de grandes agentes, se deparem com uma série de desafios para atingirem um certo nível assertividade. Nessa perspectiva, a necessidade de investir, operar e manter equipamentos, assim como a de gerir aspectos da própria carreira profissional, faz com que os artistas careçam da capacidade de autoadministração (Vicente, 2006).

Ao atuar como empresários de si mesmos, os artistas independentes se envolvem com a articulação de contato junto à estúdios, produtoras, casas de shows, e agentes culturais (Hracs \& Leslie, 2014). Adicionalmente, é importante que concentrem seus esforços em outras atividades, como na divulgação de seu trabalho, na elaboração de projetos, e em outras atividades técnicas e operacionais correspondentes à produção de conteúdo artístico-musical (Galleta, 2014).

\subsection{Enfoque sobre a Metodologia MCDA}

A tomada de decisões ocorre de forma constante em nossas vidas, em diversos aspectos e em diferentes situações, sendo essencial para a resolução dos mais simples até os mais complexos problemas. No contexto das organizações, sejam essas públicas ou privadas, o processo decisório se mostra muito relevante, pois pode influenciar diretamente no seu desempenho e longevidade (Pacheco Jr. \& Gomes, 2016).

De forma a resolver problemas de decisão complexos, recomenda-se a utilização de algum método confiável e dinâmico como apoio ao processo decisório. Para isso, os métodos tradicionais de resolução de problemas propostos pela área da Pesquisa Operacional (PO) mostram-se pouco eficientes, visto que eles buscam soluções com base no pensamento racional, 
deixando de lado a subjetividade. Nesse sentido, alguns estudiosos notaram a carência de metodologias que considerassem a multiplicidade de fatores e aspectos subjetivos presentes em situações decisionais mais complexas (Ensslin et al., 2001).

A Pesquisa Operacional é uma área do conhecimento que se utiliza de métodos científicos para a resolução de problemas, a partir da construção de modelos de decisão (ROY, 1993). Apesar de sua abordagem tradicional ter sido bastante utilizada ao longo dos anos, alguns autores passaram a desenvolver metodologias inspiradas no construtivismo, defendendo a ideia de que o conhecimento é o resultado da interação entre o sujeito e o objeto, (Landry, 1995).

O Paradigma Construtivista tem como principal pressuposto o fato de reconhecer a subjetividade dos decisores (Roy \& Vanderpooten, 1996; Ensslin et al., 2001). Assim, seguindo uma abordagem mais contemporânea da PO, a metodologia multicritério de apoio à decisão (MCDA - Multicriteria Decision Aid) surge como alternativa para avaliar situações complexas, a partir de um conjunto de indicadores qualitativos e quantitativos (Silveira Jr., 2018), o que possibiliza sua aplicação em diferentes áreas do conhecimento.

Os métodos multicritérios de apoio à decisão possuem algumas características em comum, conforme resultado de alguns estudos pioneiros de autores como Roy, Keeney, Raiffa e Saaty (Gomes, 2007; Silveira Jr., 2018). São essas: critérios de resolução de problemas conflitantes entre si; falta de clareza quanto aos critérios e às alternativas e restrições apresentadas; os critérios e as alternativas podiam estar interligados, ou refletidos uns nos outros; a solução do problema dependia de um conjunto de pessoas, com pontos de vista diferentes; alguns critérios eram quantificáveis, enquanto outros não; e por fim, as escalas para determinados critérios dependiam de sua natureza e dos dados disponíveis.

De acordo com Ensslin et al. (2001), dentre alguns fatores que podem estar presentes no processo de análise envolvendo a MCDA, estão os aspectos qualitativos, como fatores ambientais, culturais e sociais; e os aspectos quantitativos, como variáveis físicas, financeiras, de produtos, processos etc. Dessa maneira, ao final do processo decisório, são geradas recomendações que buscam atender aos distintos valores, interesses, e objetivos daqueles que estão envolvidos no processo.

Vale ressaltar que o propósito dessa metodologia não é propor uma solução ótima ao problema apresentado, como pretendem as abordagens mais tradicionalistas, senão indicar uma ou várias alternativas que podem ser escolhidas pelos decisores para satisfazer o problema. Essa metodologia serve também como ferramenta para analisar ou avaliar situações já existentes, frutos de decisões passadas, ou também para selecionar, organizar ou descrever as possíveis alternativas que serão utilizadas como base para a tomada de decisão (Gomes, 2007).

Conforme notabilizado por Quirino (2002) e Silveira Jr. (2018), a MCDA consiste fundamentalmente de três fases distintas e correlacionadas: (i) estruturação do modelo; (ii) avaliação das ações potenciais; e (iii) considerações finais a respeito da avaliação, identificando possíveis melhorias e precauções com relação ao uso do modelo.

De acordo com Ensslin et al. (2001), é salutar que os atores envolvidos no processo de tomada de decisão participem da definição dos critérios e da construção do modelo de avaliação, clarificando os aspectos mais fundamentais a serem considerados. Dessa forma, o modelo poderá transparecer um melhor entendimento da situação e do contexto envolvendo o problema, além de favorecer o desenvolvimento de conhecimento por parte dos próprios decisores (Quirino, 2002).

Segundo Silveira Jr. (2018), com o passar do tempo, o cenário que envolve um problema pode evoluir e sofrer alterações, dando abertura para o surgimento de melhores soluções. Portanto, a resolução de um problema com o emprego da MCDA deve-se aplicar àquele problema em específico em um determinado período do tempo.

Percebe-se que existe uma vasta gama de possibilidades para aplicação da MCDA, bom como desdobra-se em diversas aplicações metodológicas, conforme evidenciado por Ferreira at al. (2020), que a torna uma metodologia capaz de abranger estudos em diversas áreas do conhecimento. Com isso, levando em conta a complexidade e subjetividade que caracterizam o objeto de estudo desta pesquisa, optou-se por explorar o assunto por meio da concepção de um modelo de avaliação multicritério, a fim de procurar potenciais soluções para as deficiências identificadas na gestão colaborativa de grupos musicais (Leite, 2010). 


\section{Abordagem Metodológica}

A metodologia utilizada foi a multicritério de apoio à decisão (MCDA), por entender que se adequa aos propósitos do estudo, caracterizado por uma situação complexa com uma multiplicidade de critérios a serem avaliados. As metodologias de MCDA, segundo Ferreira et al. (2020), englobam diferentes métodos de análise de decisão, entre os quais se destaca o construtivista, que serviu de base para este estudo. Tais métodos têm sido usados com sucesso tanto para apoiar decisões que envolvem múltiplos objetivos, quanto para avaliar situações reais que enfrentam uma multiplicidade de objetivos (critérios) e que são resultado de decisões tomadas no passado (Silveira Jr., 2018; Stefani et al., 2020; Moreira et al. 2021).

Em termos metodológicos, inicialmente foi desenvolvido um modelo de avaliação, que será descrito na sequência e, posteriormente, foi realizada uma pesquisa de campo junto a grupos musicais independentes de Brasília - DF, os dados foram tabulados e tratados, foram calculadas as avaliações, parciais e global, e realizadas as respectivas análises.

\subsection{Construção do Modelo de Avaliação}

O modelo desenvolvido para avaliar a gestão colaborativa de grupos musicais independentes seguiu as premissas e os procedimentos propostos por Ensslin et al (2001), com algumas adaptações efetuadas por Silveira Jr. (2018), para sua aplicação no mundo real. Sua estrutura é constituída pelas seguintes etapas: i) Definição do rótulo do problema; ii) Identificação dos atores envolvidos no processo de avaliação; iii) Definição dos elementos de avaliação; iv) Determinação dos descritores; v) Construção das funções de valor; vi) Determinação das taxas de substituição; e vii) Construção da árvore de valor.

Apresenta-se, a seguir, o detalhamento sintético de cada uma destas etapas levados a efeito por ocasião da construção do modelo de avaliação.

\subsubsection{Definição do Rótulo}

Com o objetivo de avaliar os principais aspectos da gestão colaborativa de grupos musicais independentes, sob a perspectiva de grupos que exercem suas atividades na cidade de Brasília, definiu-se o seguinte rótulo para o modelo: Avaliação da gestão colaborativa de grupos musicais independentes de Brasília.

De acordo com Ensslin et al (2001, p. 73), “[...] a função do rótulo é delimitar o contexto decisório, de tal forma a manter o foco nos aspectos mais relevantes envolvidos com a resolução do problema do decisor”.

\subsubsection{Identificação dos Atores}

Para designar os indivíduos envolvidos no processo decisório, de forma direta ou indireta, Ensslin et al (2001) nomeiaos como intervenientes e agidos. Os intervenientes são aqueles que participam diretamente do processo decisório, tendo o maior poder de decisão e influência sobre os elementos do modelo; já os agidos são aqueles afetados pela decisão tomada, possuindo um papel mais passivo no processo.

Os intervenientes são ainda distinguidos em dois tipos de atores: (i) decisores - que detêm efetivamente o poder de decisão, assumindo as maiores responsabilidades; e (ii) facilitadores - que fornecem as ferramentas de apoio à decisão e conduzem o processo.

Neste estudo, foram considerados os seguintes atores:

- Agidos - integrantes de grupos musicais independentes de Brasília. São os beneficiários diretos do estudo realizado, mas que, neste caso específico, não participaram diretamente da construção do modelo; 
- Decisores - especialistas em produção musical e integrantes de grupos musicais independentes em atividade. Para esta pesquisa, foram convidados dois produtores e seis artistas musicais providos de conhecimentos sobre a indústria musical local e de vasta experiência na área;

- Facilitadores - os responsáveis pela condução do presente estudo.

\subsubsection{Definição dos Elementos de Avaliação}

Os elementos de avaliação (critérios) considerados no modelo constituem o núcleo do processo de avaliação. Ensslin et al (2001) propõem alguns passos para a identificação desses elementos: (i) identificação dos Elementos Primários de Avaliação (EPAs); (ii) construção de Mapas Cognitivos; e (iii) identificação dos Pontos de Vista Fundamentais (PVFs).

Os dois passos iniciais citados são utilizados como base para a identificação dos PFVs, que correspondem aos aspectos considerados pelos decisores como sendo essenciais para o processo de avaliação. Para este estudo, passou-se direto para a etapa de identificação dos PVFs, que foram estabelecidos com base nos conhecimentos e experiências dos decisores.

Ressalta-se que os PVFs, de acordo com Keeney (1996) e Quirino (2002) devem preencher os seguintes requisitos:

- Essencial - ser imprescindível para o processo de avaliação, dentro do contexto analítico;

- Controlável - ser influenciado apenas pelas ações potenciais em análise, ou seja, não extrapolar o contexto analítico;

- Completo - deve incluir todos os aspectos fundamentais para a análise que se pretende realizar;

- Mensurável - permitir que se construa descritores para medir as ações potenciais, deve permitir a mensuração da performance das ações potenciais em cada PVF, com o mínimo de ambiguidade possível;

- Não-redundante - a família de PVFs de um modelo não pode levar em conta o mesmo aspecto em mais de um PVF;

- Conciso - o conjunto de aspectos considerados deve abranger minimamente a situação em análise;

- Compreensível - deve ter um significado claro por todos os atores envolvidos no processo;

- Isolável - cada PVF deve ser independente, em termos de mensurabilidade, para que um aspecto fundamental não interfira em outro PVF; e

- Operacional - deve existir dados disponíveis para a análise, no espaço de tempo requerido.

Primeiramente, foram definidos cinco eixos básicos para avaliação, constituindo-se cada eixo em um PVF. Na sequência, em função da complexidade dos PVFs, estes foram desmembrados em Pontos de Vista Elementares (PVEs). Um dos PVEs, também em função da sua complexidade, foi desmembrado em Pontos de Vista Subelementares (PVSs), conforme estrutura apresentada no Quadro 1. 
Quadro 1. Estrutura do modelo de avaliação.

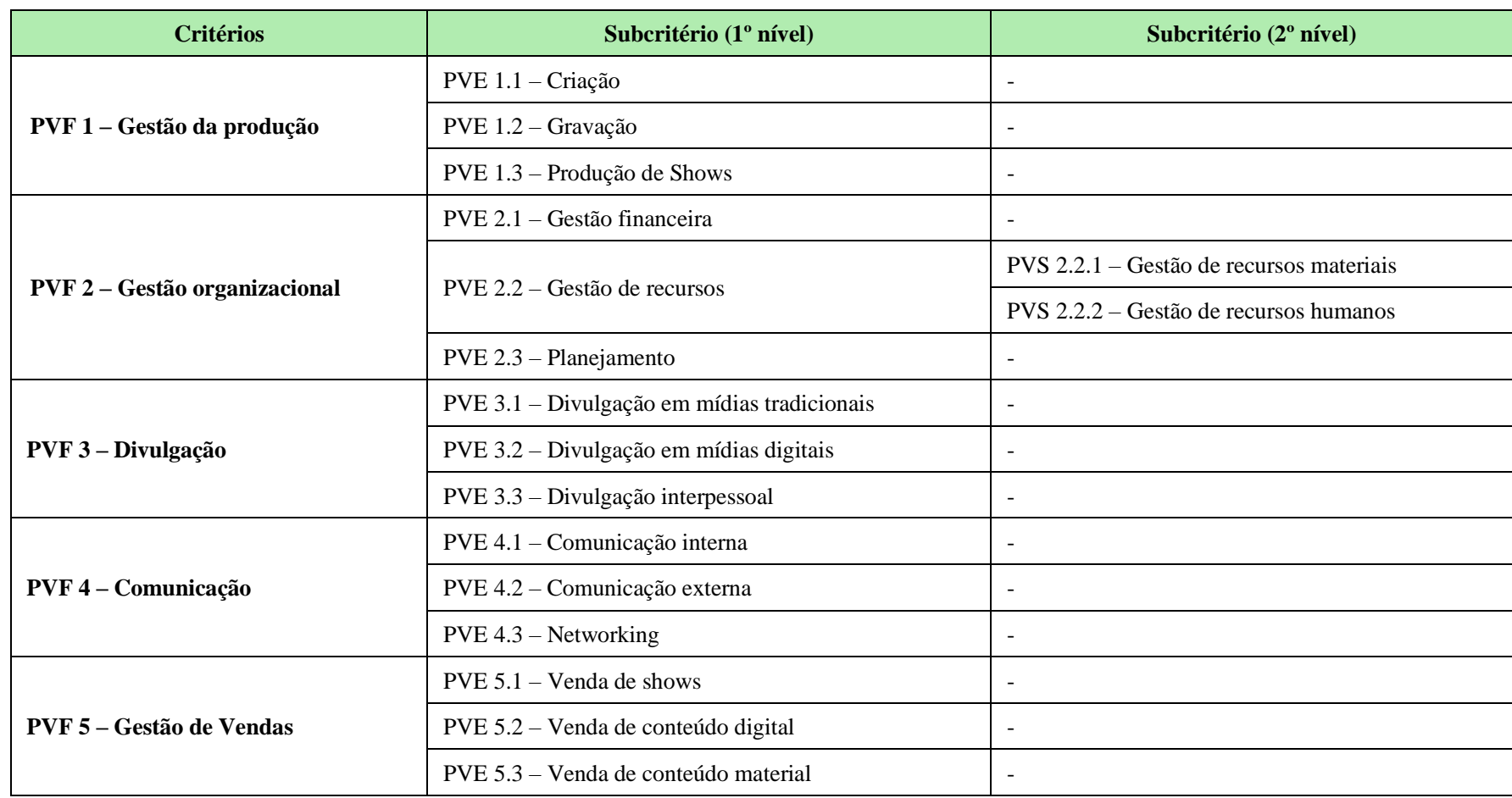

Fonte: Autores.

O próximo passo, após a definição da estrutura física, foi a estruturação dos aspectos internos ao modelo: os descritores, as funções de valor, e as taxas de substituição, que serão abordados nos tópicos seguintes.

\subsubsection{Determinação dos Descritores}

Os critérios de avaliação são moldados por duas ferramentas: os descritores e as funções de valor. De acordo com Ensslin et al (2001), “os descritores fornecem um melhor entendimento daquilo que representa a preocupação do decisor ao mensurar uma dimensão do contexto decisório. Já a função de valor proverá as informações relativas às diferenças de atratividade entre os níveis do descritor".

Os descritores correspondem a um conjunto de níveis de impacto (NI), ordenados de acordo com o sistema de valores dos decisores, que representam o desempenho das ações potenciais. No presente estudo, foram estabelecidos cinco níveis de impacto, ordenados com base na escala Likert de mensuração, a saber: i) N5 - Excelente; ii) N4 - Bom; iii) N3 - Regular; iv) N2 - Ruim; e N1 - Péssimo. Estes níveis de impacto correspondem aos descritores dos subcritérios (PVEs e PVSs) do modelo de avaliação.

\subsubsection{Construção das Funções de Valor}

Segundo Ensslin et al (2001), as funções de valor são ferramentas utilizadas para quantificar a performance das ações potenciais (critérios). Para construir as funções de valor foi utilizado o método de julgamento semântico, considerado por Quirino (2002) como o mais adequado para auxiliar os decisores na articulação de suas preferências durante o processo de avaliação. Este método utiliza-se de uma matriz de dupla entrada, onde se procede a comparação, par a par, dos níveis de impacto, fins determinar as diferenças de atratividade entre as ações potenciais (Beinat, 1995). 
Para o cálculo das funções de valor foi utilizado o método Measuring Attractiveness by a Categorical Based Evaluation Technique (Macbeth), desenvolvido por Bana e Costa \& Vanisck (1995). Esse método se utiliza de programação linear para determinar o valor numérico que melhor representa o julgamento semântico dos decisores (Wagner, 1986).

Para fins de exemplificação, a Figura 1 apresenta a matriz semântica utilizada para definir a função de valor do PVE 2.1 - Comunicação interna.

Figura 1. Matriz semântica do PVE 2.1 - Comunicação interna.

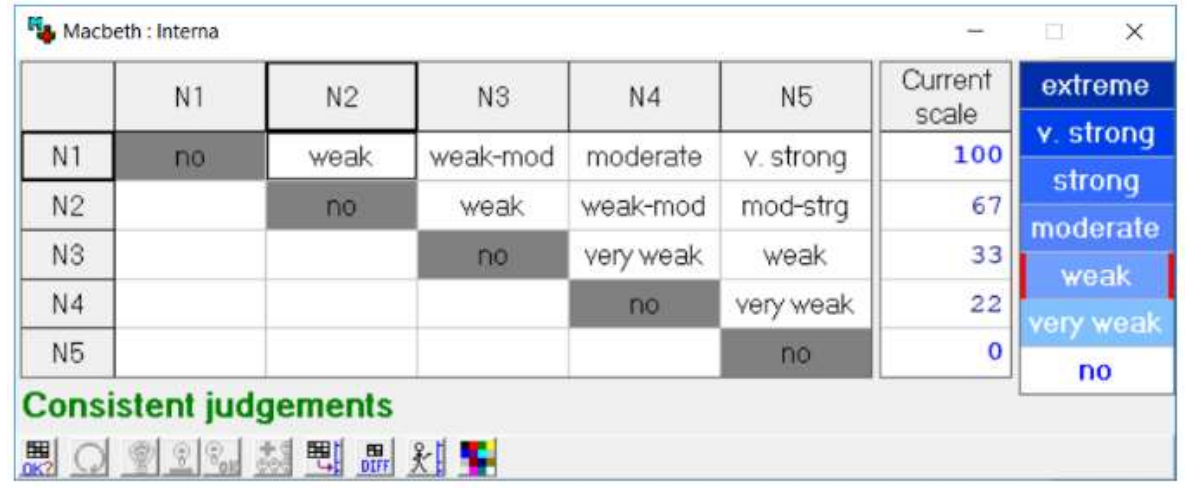

Fonte: Macbeth.

Com base nos níveis de atratividade determinados pelos decisores, construiu-se uma matriz semântica para cada PVE conforme exemplificada na Figura 1, na qual deve-se considerar $\mathbf{a}_{\mathrm{ij}}$ um elemento qualquer, onde " $\mathrm{i}$ ” representa a linha em que o elemento se posiciona na matriz e “j” representa a coluna em que o elemento se posiciona. Quirino (2002) destaca que para manter a consistência da matriz semântica, torna-se necessário o cumprimento das seguintes propriedades:

- Na linha "ip" $\rightarrow \mathbf{a}_{\mathbf{i j}} \leq \mathbf{a}_{\mathbf{i j}+\mathbf{1}} \leq \mathbf{a}_{\mathbf{i j}+\mathbf{2}} \leq \ldots . . . \leq \mathbf{a}_{\mathbf{i j}+\mathbf{n}}$;

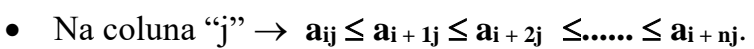

De forma a evitar uma incompatibilidade no sistema de equações que formam a programação linear, é imprescindível que sejam observadas as propriedades supracitadas, além de satisfazerem as condições matemáticas indicadas abaixo, onde A corresponde ao conjunto de ações potenciais (Ensslin et al, 2001):

- Para todo a, b $\in$ A, v(a) > v(b) se, e somente se, para o avaliador "a" for mais atrativa que "b" (a P b) ("a" é preferível a "b");

- Para todo a, b $\in$ A, v(a) = (b) se, e somente se, para o avaliador "a" for indiferente a "b' (a I b) ("a" é indiferente a "b");

- Para todo $\mathrm{a}, \mathrm{b}, \mathrm{c}, \mathrm{d} \in \mathrm{A}, \mathrm{v}(\mathrm{a})-\mathrm{v}(\mathrm{b})>\mathrm{v}(\mathrm{c})-\mathrm{v}(\mathrm{d})$ se, e somente se, para o avaliador a diferença de atratividade entre "a" e "b" for maior que a diferença de atratividade entre "c" e "d".

O passo seguinte diz respeito à determinação das taxas de substituição, que correspondem aos pesos dos critérios e subcritérios no modelo de avaliação.

\subsubsection{Determinação das Taxas de Substituição}

As taxas de substituição são ferramentas por meio das quais se expressam as preferências dos decisores, assim como a perda de performance que uma ação potencial deve sofrer para compensar um ganho na outra (Roy, 1996). As taxas de substituição também podem ser caracterizadas como pesos (Ensslin et al, 2001). 
Existem vários métodos para se determinarem as taxas de substituição. Neste estudo, seguindo a orientação de Quirino (2002), utilizou-se o método dos pesos balanceados (swing weights) para a determinação das taxas de substituição dos PVFs (critérios) e o método de comparação par a par para os PVEs (subcritérios) Vide os pesos dos critérios e subcritérios na árvore de valor da Figura 2.

\subsubsection{Construção da Árvore de Valor}

Com a estrutura do modelo de avaliação definida, construiu-se a correspondente árvore de valor, a qual contempla os critérios, subcritérios e as respectivas taxas de substituição.

De acordo com Ensslin et al. (2001), a árvore de valor representa os pontos de vista por meio de uma estrutura arborescente, a qual provê maior praticidade e compreensão com relação aos critérios e subcritérios utilizados na avaliação. Na estrutura apresentada na Figura 2, os pontos de vista estão ligados uns aos outros, de forma hierárquica, a saber: um objetivo global estratégico, cinco PVFs, quinze PVEs, dois PVSs e as taxas de substituição (pesos) de cada item.

Figura 2. Árvore de Valor.

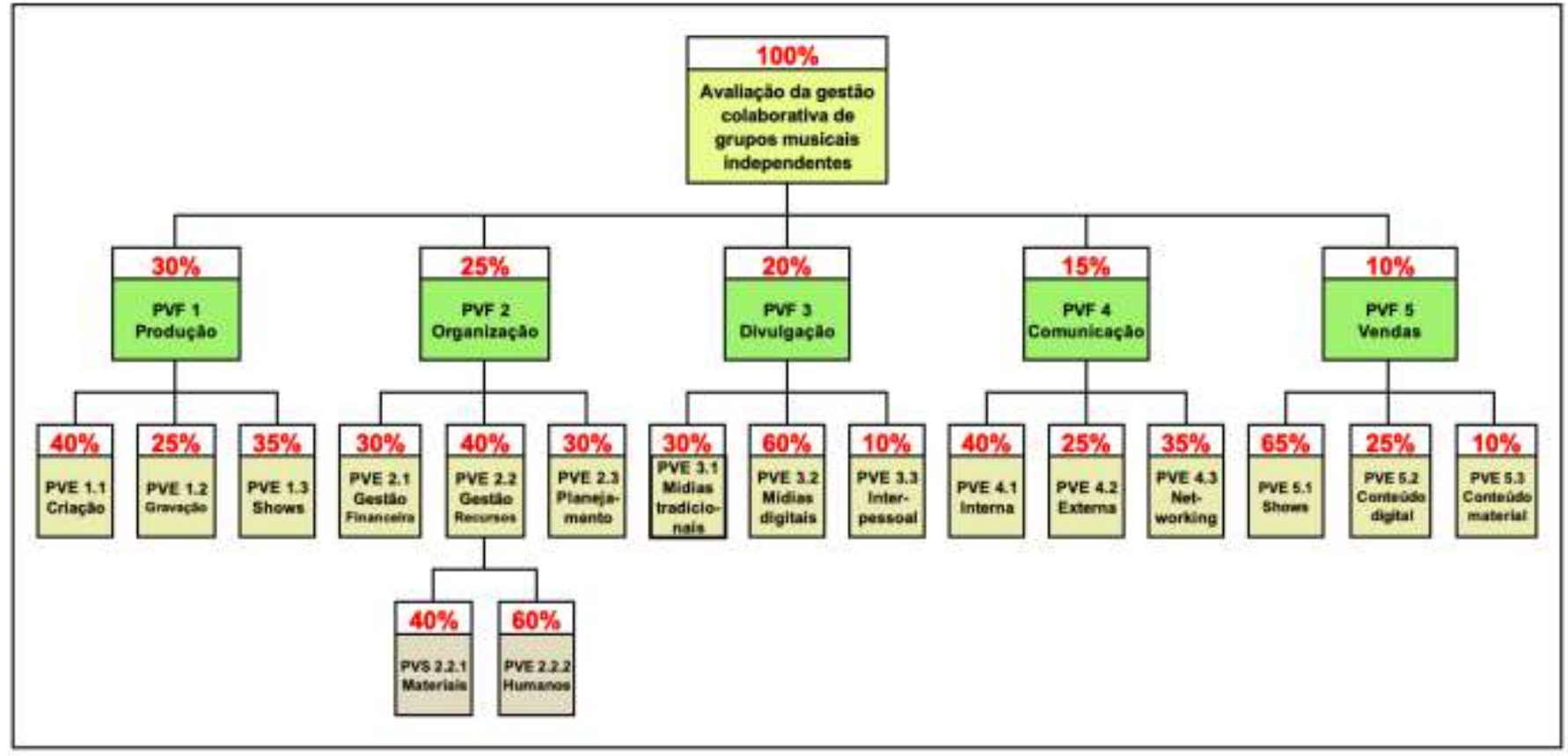

Fonte: Autores.

Com a árvore de valor, conclui-se a estrutura do modelo multicritério de avaliação em si, no entanto abordar-se-á nos próximos subitens dois aspectos que, embora não façam parte integrante do modelo de avaliação, estão diretamente relacionados ao mesmo: Procedimentos para o cálculo da avaliação; e Análise de sensibilidade.

Para fins de operacionalização da pesquisa de campo junto aos grupos musicais independentes, elaborou-se um questionário tendo por escopo os pontos de vista elementares e subelementares, ou seja, cada PVE e PVS deu dar origem a uma pergunta do questionário, e os descritores (conjunto de níveis de impacto) constituíram-se nas alternativas de respostas.

Por ocasião da tabulação e tratamentos dos dados da pesquisa de campo, estes foram convertidos de qualitativos para quantitativos, com a valoração dos PVEs e PVFs, constituindo-se no insumo para o cálculo da avaliação final do estágio em que se encontra a gestão colaborativa dos grupos musicais independentes do Distrito Federal, conforme será demonstrado no subitem seguinte. 


\subsection{Procedimento para o Cálculo das Avaliações}

Conforme indicado anteriormente, a coleta de dados se deu por meio da aplicação de um questionário junto a representantes de grupos musicais independentes de Brasília. Após a coleta, realizou-se a tabulação e o lançamento dos dados no software Hiview3, que definiu as respectivas pontuações dos critérios de avaliação, com base no modelo estabelecido.

Para o cálculo das avaliações dos PVFs, utilizou-se a fórmula de agregação abaixo, proposta por Ensslin et al. (2001), com os devidos ajustes:

$$
A(P V F)=\sum_{j=1}^{n}\left[\sum_{i=1}^{m} p i .(F V i R j)\right] .1 / n
$$

Onde:

- $\mathrm{A}(\mathrm{PVF})=$ avaliação do PVF;

- $\quad$ pi = taxa de substituição (peso) do PVE i;

- $(F V i E j)=$ função de valor dos respondentes j impactados no PVE i;

- $\mathrm{m}=$ número de subcritérios (3);

- $\mathrm{n}=$ número de respondentes (42).

Tal equação está sujeita às seguintes restrições:

- O somatório das taxas de substituição deve ser igual a $1(\mathrm{p} 1+\mathrm{p} 2+\mathrm{p} 3=1 \rightarrow 100 \%)$;

- O valor das taxas de substituição deve ser maior do que zero e menor do que $1(0<$ pi < 1 , para $\mathrm{i}=1,2$, e 3);

Com a avaliação dos PVFs definida, calculou-se a avaliação global por meio da fórmula apresentada a seguir, seguindo os preceitos definidos por Ensslin et al., (2001):

$$
A G=\sum_{j=1}^{n}\left[\sum_{i=1}^{m} x i \cdot y i(F V R j)\right] .1 / n
$$

Onde:

- $\mathrm{AG}=$ avaliação global;

- $\quad$ yi $(E j)=$ pontuação parcial do grupo j nos critérios 1, 2, 3, 4 e 5;

- $\quad x i$ = taxa de substituição dos critérios 1, 2, 3, 4 e 5;

- $\mathrm{n}$ = número de respondentes (42);

- $\mathrm{k}=$ número de critérios (5).

Tal equação está submetida às seguintes restrições:

- o somatório das taxas de substituição dos PVFs deve ser igual a $1(\mathrm{y} 1+\mathrm{y} 2+\mathrm{y} 3+\mathrm{y} 4+\mathrm{y} 5=1 \rightarrow 100 \%)$;

- O valor das taxas de substituição deve ser maior do que zero e menor do que $1(0<$ yi < 1, para i = 1, 2, 3, 4 e 5);

Estas fórmulas são suficientes e bastante para se calcular a avaliação dos critérios e a avaliação global, a partir dos dados levantados na pesquisa de campo, após serem tratados pelo software Hiview3.

\section{Apresentação e Análise dos Dados}

A pesquisa de campo sobre o estado da arte da gestão colaborativa de grupos musicais independentes de Brasília foi realizada junto a 42 representantes desses grupos, no quarto trimestre de 2019, portanto, um pouco antes do início da pandemia do covid-19. Logo em seguida, os dados colhidos foram tabulados e tratados pelo software Hiview3 com base no modelo de avaliação desenvolvido, e serão apresentados e analisados por ponto de vista fundamental (crité. Na sequência, apresentar-se-á a avaliação global, correspondente à consolidação das avaliações dos PVFs. 


\subsection{Análise do PVF 1 - Gestão da Produção}

A participação do PVF 1 no contexto global foi de 30\%, conforme peso determinado pelos decisores. Os PVEs que o compõem são: 1.1 - Criação, com peso de 40\%; 1.2 - Gravação, com peso de 25\%; e 1.3 - Shows, com peso de $35 \%$.

A pontuação atingida pelo PVF 1, em uma escala de 0 até 10 , foi de $\mathbf{5 , 5 8}$, correspondente à média ponderada dos PVEs, conforme demonstrado na Quadro 2.

Quadro 2. Avaliação do PVF 1

\begin{tabular}{|l|c|c|c|}
\hline \multicolumn{1}{|c|}{ PVEs } & Pesos & Pontuação dos PVEs & Avaliação do PVF 3 \\
\cline { 1 - 2 } Criação & $40 \%$ & 6,67 & \multirow{2}{*}{5} \\
\cline { 1 - 2 } Gravação & $25 \%$ & 6,73 & \multirow{2}{*}{6,58} \\
\cline { 1 - 2 } Shows & $35 \%$ & 3,53 & \\
\hline
\end{tabular}

Fonte: Autores.

Essa nota representa uma avaliação pouco satisfatória, em virtude de se aproximar da nota mínima aceitável, que seria cinco, indicando que existem melhorias a serem implementadas com relação à gestão colaborativa da produção nos grupos musicais.

Com relação ao PVE 1.1, a pontuação obtida foi de $\mathbf{6 , 6 7}$, indicando que a criação nos grupos musicais independentes é avaliada positivamente, apesar de haver espaço para melhorias. O processo de criação é desenvolvido conforme a experiência e a interação entre os participantes dos grupos musicais, o que o torna um elemento de difícil avaliação, cuja satisfação depende do relacionamento e do entrosamento existente entre os seus integrantes, além da habilidade de composição e da afinidade de cada indivíduo em ralação às características das músicas criadas - a qual pode ser altamente subjetiva.

Quanto ao PVE 1.2, a pontuação obtida foi de 6,73, a mais alta entre os PVEs do PVF 1. Essa pontuação indica que a gravação não é totalmente satisfatória e que existe margem para implementação de melhorias. Isto se deve ao fato de que, conforme Gohn (2008), o processo de gravação musical é uma das atividades de maior complexidade na produção musical, pois exige conhecimentos técnicos e práticos para o uso de equipamentos, softwares, e manipulação dos arquivos gerados após a captação de som.

Outro ponto que justifica a nota obtida pelo PVE 1.2 está relacionado ao fato de o processo de gravação ser uma atividade frequentemente terceirizada, ou feita em parceria com profissionais do ramo; pois, caso contrário, os músicos precisariam dedicar boa parte de seu tempo e de seus esforços para realizarem um trabalho de boa qualidade. Por essa razão, conforme a ótica de Hracs (2012) e Vogel (2011), é costume as bandas realizarem gravações de demonstração de suas músicas (conhecidas como demos), que servem como rascunho ou ideia prévia da gravação pretendida. Por meio das demos, os artistas também conseguem atrair potenciais parceiros, como produtores ou gravadoras que venham a se interessar pelo material.

Por fim, o PVE 1.3 atingiu a pontuação de 3,53, a mais baixa entre os PVEs que compõem o PVF 1, evidenciando que as ações envolvendo a gestão e a produção de shows são avaliadas de forma negativa, o que aponta uma deficiência relacionada a esse ponto. Uma agenda pouco movimentada e a pouca experiência de palco, bem como a baixa exposição comercial dos grupos musicais, também podem ser alguns dos fatores que explicam a insatisfação dos participantes da pesquisa com relação ao PVE avaliado.

Este PVE abarca diversos fatores técnicos, ambientais e artísticos, tais como: preparação de shows - que inclui ensaios, escolha de repertório, escolha de figurino, etc.; performance, que diz respeito ao desempenho e à qualidade de execução artística 
e musical; assim como aspectos relacionados ao som, iluminação, cenografia, e ao ambiente, que na maioria das vezes não dependem dos grupos em si, mas das casas de show, de produtores, e demais agentes.

A baixa pontuação do PVF 1 relaciona-se também com a necessidade que os artistas têm de lidar com uma série de atividades que fazem parte da produção musical. Além de se preocuparem com a criação de músicas, eles precisam se familiarizar com os detalhes das atividades do processo de produção. Desse modo, assim como discutido por Nakano (2010), ao se depararem com as dificuldades relacionadas a esses processos, os artistas procuram a ajuda de parceiros pontuais, usualmente autônomos, que sejam capazes de oferecer um bom serviço. Esse relacionamento, por muitas vezes, é baseado em reconhecimento e confiança mútua.

\subsection{Análise do PVF 2 - Gestão Organizacional}

Com relação ao contexto global da avaliação, o PVF 2 teve uma participação de $25 \%$ do total. Constituindo-se dos PVEs: 2.1 - Gestão financeira, com peso de 30\%; 2.2 - Gestão de recursos, com peso de 40\%; e 2.3 - Planejamento, com peso de $30 \%$. Após o cômputo da avaliação, este PVF obteve uma pontuação de $\mathbf{3 , 9 7}$, expondo a fragilidade dos PVEs relativos à gestão colaborativa dos grupos musicais independentes. Vide o detalhamento das pontuações na Quadro 3.

Quadro 3. Avaliação do PVF 2.

\begin{tabular}{|l|c|c|c|}
\hline \multicolumn{1}{|c|}{ PVEs } & Pesos & Pontuação dos PVEs & Avaliação do PVF 3 \\
\cline { 1 - 2 } Gestão financeira & $30 \%$ & 3,42 & \multirow{2}{*}{3,97} \\
\cline { 1 - 2 } Gestão de recursos & $40 \%$ & 4,78 & \\
\cline { 1 - 2 } Planejamento & $30 \%$ & 3,45 & \\
\hline
\end{tabular}

Fonte: Autores.

Os PVEs estabelecidos neste item representam algumas práticas da gestão organizacional consideradas como fundamentais em grupos musicais independentes, assim como na maioria das empresas, pois refletem o cuidado que se tem com o planejamento das ações e com os recursos disponíveis ao grupo. A avaliação negativa deste PVF pode ser um indício de que boa parte desses grupos não estão com seus objetivos devidamente alinhados, ou de que há uma falta de comprometimento com relação à organização.

O PVE 2.1 obteve uma nota de $\mathbf{3 , 4 2}$, que pode ser interpretada como sendo ruim. Tal avaliação pode ser justificada pelo fato de o mercado da música independente ser pouco rentável, fazendo com que os artistas não consigam recuperar grande parte dos custos da exploração da atividade musical. Segundo estudo de Nakano (2010), isso se deve, em parte, à impossibilidade de garantir o sucesso de um artista, fazendo com que estes tenham que correr riscos e aceitar as incertezas do mercado.

Com relação ao PVE 2.2, a avaliação obtida foi de 4,78, o que reflete uma insatisfação relacionada à gestão de recursos praticada pelos grupos musicais. Vale ressaltar que esse PVE, em função da sua complexidade, foi desmembrado em dois pontos de vista subelementares (PVSs): o PVS 2.2.1 refere-se à gestão de recursos materiais (correspondente a 40\% do PVE), enquanto o PVS 2.2.2 diz respeito à gestão de recursos humanos (correspondente a $60 \%$ do PVE).

A pontuação do PVE 2.2, apesar de baixa, é a maior dentre os itens do PVF 2. No que se refere aos recursos materiais, a avaliação negativa pode ser explicada, em partes, pelo alto custo que envolve a compra e manutenção de equipamentos musicais. Por consequência, muitas bandas independentes possuem poucos recursos disponíveis, utilizando-se do apoio de parceiros, principalmente nas ocasiões de gravação e apresentações ao vivo. 
Por outro lado, no tocante aos recursos humanos, com a avaliação obtida entende-se que podem existir algumas diferenças entre as necessidades e os interesses dos indivíduos com relação ao grupo musical do qual fazem parte. Um baixo aproveitamento dos talentos individuais, de forma com que as ações do grupo acarretem poucos resultados positivos, pode ser outra explicação para a nota do PVE 2.2. Conforme Búrigo et al. (2016), através de uma estrutura organizacional que promove ações em conjunto, procurando coordenar diferentes pontos de vista, será possível favorecer o interesse coletivo.

Finalmente, o PVE 2.3 obteve a pontuação de $\mathbf{3 , 4 5}$, representando o descontentamento dos respondentes para com o Planejamento em seus respectivos grupos. O resultado desta avaliação aponta para uma insatisfação com respeito aos planos de ação de seus grupos e das diretrizes que moldam suas decisões.

De acordo com Vicente (2006), os artistas da atualidade precisam se preocupar com uma série de questões envolvendo não só a prática musical, mas também diversos outros fatores, tais como: i) necessidade de investir e de controlar despesas e receitas; ii) manutenção e utilização sustentável dos recursos disponíveis; e iii) necessidade de coordenar ações e trabalhar em equipe em prol de um objetivo em comum; entre outros processos que envolvem a gestão da própria carreira profissional. A falta de atenção e cuidado com esses fatores pode ser uma justificativa para a avaliação negativa do PVF 2

Visando melhorar a satisfação dos grupos musicais independentes no que diz respeito ao PVF 2, recomenda-se que estes procurem desenvolver um bom controle sobre seus recursos financeiros, materiais e humanos, por meio de ações planejadas, e tomando decisões a fim de garantir que o grupo tenha dinheiro suficiente para investimentos, manutenção de equipamentos, e desenvolvimento de habilidades. Para isso, é importante que exista um engajamento entre os integrantes de um grupo, o que favorece a convergência de interesses e estimula o comprometimento da equipe.

\subsection{Análise do PVF 3 - Divulgação}

O PVF 3 possui um peso de $20 \%$ na avaliação global, constituindo-se pelos PVEs: 3.1 - Divulgação em mídias tradicionais, com 30\% de peso; 3.2 - Divulgação em mídias digitais, com 60\% de peso; e 3.3 - Divulgação interpessoal, com 10\% de peso. O referido PVF obteve a pontuação de $\mathbf{2 , 7 3}$, conforme demonstrado na Quadro 4, caracterizando-se o critério com a menor nota, entre os avaliados.

Quadro 4. Avaliação do PVF 3.

\begin{tabular}{|l|c|c|c|}
\hline \multicolumn{1}{|c|}{ PVEs } & Pesos & Pontuação dos PVEs & Avaliação do PVF 3 \\
\cline { 1 - 2 } Divulgação mídias tradicionais & $30 \%$ & 1,43 & \multirow{2}{*}{2,73} \\
\cline { 1 - 2 } Divulgação mídias digitais & $60 \%$ & 3,16 & \\
\cline { 1 - 2 } Divulgação interpessoal & $10 \%$ & 4,05 & \\
\hline
\end{tabular}

Fonte: Autores.

Compreende-se, por meio dos resultados obtidos, que a divulgação dos grupos musicais representa a maior preocupação entre as atividades mapeadas, salientando barreiras para o alcance de grandes públicos e para a veiculação de seus produtos. Segundo Galleta (2014), historicamente é possível perceber que as produções independentes no Brasil são mais voltadas para públicos segmentados e de nicho, os quais procuram alternativas a conteúdos mais privilegiados no mercado mainstream (popular). Ou seja, são produções que tradicionalmente não são voltadas ao alcance de públicos de massa.

A exemplo do descrito acima, o PVE 3.1 demonstrou a segunda pior avaliação dentre todos os PVEs incluídos na pesquisa de campo, atingindo apenas $\mathbf{1 , 4 3}$ pontos. Isso pode ser justificado levando em conta que os meios de comunicação 
tradicionais, como TV, rádio, revistas e jornais, são caracterizados por serem veículos de informação de massa, priorizando conteúdo de maior valor comercial. Não sendo muito acessíveis a produções independentes.

Para o PVE 3.2, a pontuação resultante foi de 3,16, refletindo o baixo desempenho com relação à divulgação por meio de mídias digitais. Um dos fatores que contribuem para essa pontuação é o imenso volume de conteúdo presente nas plataformas e redes de compartilhamento acessíveis via internet. Com isso, para que um conteúdo compartilhado alcance uma quantidade relevante de usuários, é preciso direcionar as publicações por meio de impulsionamento que exige gasto de tempo e/ou dinheiro.

Quanto ao PVE 3.3, sua pontuação foi de $\mathbf{4 , 0 5}$, o que corresponde à maior pontuação com relação ao PVF 3 . A avaliação pouco satisfatória demonstra que as ações de divulgação interpessoal (ou boca a boca), não são praticadas de forma muito efetiva, o que pode ser explicado pela pouca proximidade com o público, assim como pela baixa proatividade dos integrantes ao fazer contato direto com potenciais parceiros ou seguidores. Tal desempenho pode prejudicar os artistas independentes na tentativa de promover seus trabalhos em momentos específicos, de forma a ocasionar situações favoráveis a negociações e à troca de informações.

A pontuação do PVF 3 indica a grande insatisfação dos grupos musicais independentes no que diz respeito à divulgação de seus trabalhos. Entre as possíveis explicações para este caso, podem-se citar: a crescente necessidade de estar presente entre os meios digitais para serem notados pelo público; a importância da imagem do artista no cenário musical; a dificuldade para manipular ferramentas e softwares de divulgação; e a dificuldade de coordenar as ações de divulgação com as demais atividades que lhes correspondem.

Para reverter esse cenário, os artistas independentes precisam assumir a responsabilidade pelas ações de marketing e comunicação, pois se trata de um processo fundamental para a distribuição de conteúdo e para atrair a atenção de eventuais parceiros, produtores e do público em geral. Para isso, de acordo com Anderson (2006) e Galleta (2014), as redes sociais propiciam canais, ferramentas, e softwares para o encontro e cultivo de nichos, segmentos e mercados que podem facilitar o processo de divulgação e trazer resultados positivos.

\subsection{Análise do PVF 4 - Comunicação}

O PVF 4 possui uma participação de $15 \%$ a avaliação global, tendo sido desmembrado em PVEs: 4.1 - Comunicação interna, com peso de 40\%; 4.2 - Comunicação externa, com peso de 25\%; e 4.3 - Networking, com peso de $35 \%$. A pontuação obtida foi de 4,20 pontos, indicando que as atividades que envolvem a comunicação dos grupos musicais independentes não estão de acordo com as expectativas de grande parte dos respondentes. Vide o detalhamento da pontuação obtida na Quadro 5.

Quadro 5. Avaliação do PVF 4.

\begin{tabular}{|l|c|c|c|}
\hline \multicolumn{1}{|c|}{ PVEs } & Pesos & Pontuação dos PVEs & Avaliação do PVF 3 \\
\cline { 1 - 2 } Comunicação interna & $40 \%$ & 5,32 & \multirow{2}{*}{4} \\
\cline { 1 - 2 } Comunicação externa & $25 \%$ & 3,10 & \\
\cline { 1 - 2 } Networking & $35 \%$ & 3,69 & \\
\hline
\end{tabular}

Fonte: Autores.

A pontuação do PVE 4.1, referente à comunicação interna, foi de 5,32, a qual pode ser tratada como pouco satisfatória, visto que expressa a instabilidade presente nos processos de interação e de troca de conhecimentos entre os integrantes dos grupos musicais. De acordo com Almeida (2005) a constituição de uma unidade de trabalho dinâmica requer que os envolvidos convivam com as ambiguidades e os conflitos de interesses presentes nos relacionamentos. 
No que diz respeito ao PVE 4.2, a pontuação obtida foi de $\mathbf{3 , 1 0}$, a mais baixa dentre os itens que compõem o PVF 4. Tal pontuação, que aponta para a deficiência do conjunto de ações e processos que envolvem a comunicação entre o grupo e o público geral, mostra que a comunicação externa não está entre os focos dos grupos musicais independentes, ou que não está sendo praticada de forma eficiente. Essa questão pode ser explicada pela baixa proximidade entre os grupos e o público, assim como pela gestão ineficiente dos canais digitais que funcionam como meios de comunicação e de divulgação.

O PVE 4.3, com uma avaliação de $\mathbf{3 , 6 9}$ pontos, também não se mostrou um elemento avaliado muito positivamente entre os participantes da pesquisa. As redes de contato (networks) são essenciais no mercado da música, principalmente na cena independente, visto que as bandas precisam ter contatos e parcerias para a realização de diversas atividades, como as que oferecem dificuldades técnicas ou que requerem conhecimentos específicos, exteriores ao grupo.

Essa pontuação negativa, pode ser indício do isolamento dos grupos musicais independentes, seja pelo insucesso nas tentativas de criar e manter contatos relevantes, ou por conta dos seus sistemas de produção pouco abertos. De acordo com Aquino (2002), por meio de sistemas de produção mais abertos, promove-se uma maior circulação de conhecimento e experiências, estimulando um processo de retroalimentação entre a rede e seus colaboradores. Além disso, Rodrigues e Sellito (2007), defendem que desenvolver e manter uma boa e ampla rede de contatos pode servir como uma vantagem competitiva para artistas independentes.

Uma boa comunicação externa é um fator essencial para os artistas que dependem do interesse e do engajamento do público para gerar lucro, uma vez que as pessoas se utilizam dos seus canais de comunicação para acompanhar suas atividades, agenda de shows, e lançamentos de conteúdo. A partir disso, os grupos musicais independentes devem se preocupar um pouco mais com as práticas que envolvem a comunicação com o público, o que pode aumentar o número de seguidores, provendo maior notabilidade e disseminando um maior volume de informações. Os resultados desse esforço podem ser observados, sobretudo, na presença do público nos shows.

Adicionalmente, vale ressaltar, conforme abordado por Min et al. (2005), que o trabalho colaborativo entre organizações, assim como a atuação conjunta de membros de diferentes grupos traz maiores benefícios do que a ação isolada. Com isso, os processos de tomada de decisões e de resolução de problemas são potencializados, além de gerar maior eficiência nas negociações e na utilização de recursos.

Visando à melhoria dos itens avaliados no PVF 4, os integrantes dos grupos musicais independentes devem aumentar seus esforços no que diz respeito às práticas colaborativas e à comunicação, dentro e fora do grupo. Com isso, o relacionamento entre os envolvidos, assim como a sinergia do grupo, pode alcançar níveis mais satisfatórios.

\subsection{Análise do PVF 5 - Gestão de Vendas}

A avaliação da gestão de vendas, representada pelo PVF 5, obteve a pontuação de $\mathbf{2 , 8 8}$, conforme demonstrado no Quadro 6, a segunda mais baixa entre os pontos de vista avaliados na pesquisa de campo. Os PVEs que compõem este PVF são: 5.1 - Venda de shows, com peso de 65\%; 5.2 - Venda de conteúdo digital, com peso de 25\%; e 5.3 - Venda de conteúdo material, com peso de $10 \%$. A baixa pontuação deste item representa, principalmente, o baixo retorno financeiro e o baixo retorno comercial dos grupos musicais independentes. 
Quadro 6. Avaliação do PVF 5.

\begin{tabular}{|l|c|c|c|}
\hline \multicolumn{1}{|c|}{ PVEs } & Pesos & Pontuação dos PVEs & Avaliação do PVF 3 \\
\hline Venda de shows & $65 \%$ & 3,50 & \multirow{2}{*}{2,88} \\
\cline { 1 - 2 } Venda de conteúdo digital & $25 \%$ & 1,90 & \\
\cline { 1 - 2 } Venda de conteúdo material & $10 \%$ & 1,26 & \\
\hline
\end{tabular}

Fonte: Autores.

Quanto ao PVE 5.1, a pontuação resultante foi de 3,50, a maior dentre os elementos incluídos no PVF 5, porém que não se traduz como satisfatória. Essa atividade é umas das mais cruciais no exercício da música, pois trata-se do momento auge do artista, quando este apresenta o seu trabalho ao público, e colhe os frutos de seus esforços, tais como reconhecimento e renda.

Em consonância com os argumentos de Hracs \& Leslie (2014), entre alguns dos fatores que podem justificar a dificuldade em vender shows, estão: o fato de os músicos independentes terem de atuar como seus próprios agentes e produtores; a dificuldade em divulgar conteúdo e promover shows; e a necessidade de estabelecer uma boa rede de contatos e parcerias para conseguirem oportunidades na cena musical.

No que diz respeito ao PVE 5.2, a avaliação realizada foi ainda mais baixa, resultando em 1,90 pontos. Seguindo a linha de estudo de Nakano (2010), a dificuldade encontrada em vender produtos digitais está relacionada com os processos de apropriação da renda presentes nas mídias de compartilhamento e reprodução por internet. Principalmente por conta das alternativas gratuitas no mercado e das falhas nos mecanismos de apropriação de conteúdo. Complementarmente, apesar da facilidade de acesso a aplicativos e softwares de música e de vídeo, o baixo retorno financeiro pode ser resultado de uma má divulgação, da falta de investimentos, e da baixa qualidade do conteúdo.

Por fim, o PVE 5.3 apresenta a pior nota obtida em toda a pesquisa de campo, com 1,26 pontos, deixando clara a grande insatisfação dos participantes com relação à venda de conteúdo material. Tal fenômeno não é de grande surpresa, pois a venda de objetos, discos, camisetas, e outros materiais físicos não é uma atividade inerente a todos os grupos musicais independentes, pois necessita de investimentos e o retorno obtido geralmente é muito baixo.

As apresentações ao vivo têm ganhado cada vez mais importância ao longo do tempo, especialmente pela queda na relevância dos fonogramas e outras mídias físicas. Dessa forma, como possível solução para o baixo volume de vendas realizadas pelos grupos musicais independentes, está a utilização de discos e outros itens materiais como instrumentos para a promoção de shows e para a retenção de seguidores.

Por fim, de forma a melhorar as pontuações obtidas pelo PVF 5, aconselha-se a investir nas performances ao vivo, pois, além do potencial de atratividade que essa atividade possui com relação às outras, o contato direto com o público pode impulsionar os ganhos do negócio. Isso se deve ao fato de as performances envolverem uma série de elementos estéticos e sociais, definindo a identidade dos artistas, e conectando-os com o público presente por meio de um processo de interação direta.

\subsection{Análise da Avaliação Global}

A avaliação global da gestão colaborativa de grupos musicais independentes de Brasília obteve uma nota de 4,13, em uma escala de 0 a 10. Apresenta-se na Quadro 7 a composição desta nota, que corresponde à média ponderada das pontuações atribuídas aos PVFs. 
Quadro 7. Avaliação Global.

\begin{tabular}{|l|c|c|c|}
\hline \multicolumn{1}{|c|}{ PVEs } & Pesos & Pontuação dos PVFs & Avaliação Global \\
\hline 1 - Gestão da produção & $30 \%$ & 5,59 & \\
\cline { 1 - 2 } 2 - Gestão organizacional & $25 \%$ & 3,97 & \multirow{2}{*}{4,13} \\
\cline { 1 - 2 } 3 - Divulgação & $20 \%$ & 2,70 & \\
\cline { 1 - 2 } 4 - Comunicação & $15 \%$ & 4,17 & \\
\cline { 1 - 2 } 5 - Gestão de vendas & $10 \%$ & 2,91 & \\
\hline
\end{tabular}

Fonte: Autores.

A nota da avaliação global foi muito baixa, demonstrando a insatisfação dos respondentes da pesquisa com a gestão colaborativa dos grupos musicais independentes de Brasília. Dentre os fatores que justificam esta baixa pontuação, destacam-se: a dificuldade de assimilação, por parte dos grupos musicais independentes, de que a soberania de suas carreiras está atrelada ao êxito de suas práticas empreendedoras no mercado musical; a fragilidade presente em suas redes de contatos e parcerias, as quais exercem grande influência sobre o desempenho das práticas e articulações colaborativas do grupo; a precariedade das suas práticas de gestão, assim como a precariedade dos processos de distribuição e venda de seus produtos; e, enfim, o baixo alcance de público para conseguir gerar receitas e tornar o negócio em uma atividade sustentável.

\subsection{Aplicação da Análise de Sensibilidade}

É importante investigar até que ponto o modelo multicritério construído é robusto o suficiente para inferir credibilidade aos resultados obtidos (Quirino, 2002). Para isso, sugere-se a realização de uma análise de sensibilidade. Ensslin et al. (2001) propõem que esta análise seja realizada com base na variação das taxas de substituição dos critérios, provocando pequenas alterações em seus parâmetros, de forma a verificar o impacto causado por tais alterações na mensuração final. Para que o modelo seja considerado robusto, essas alterações não podem afetar significativamente a avaliação global.

Considerando que as taxas de substituição dos critérios (pesos) devem ser iguais a 1 (100\%), a alteração efetuada no parâmetro de cada critério provoca mudanças nos parâmetros dos demais. Com isso, para calcular as novas taxas de substituição, Ensslin et al. (2001) sugerem a utilização da fórmula a seguir:

$$
\mathrm{P} n^{\prime}=\frac{p n \cdot\left(1-p i^{\prime}\right)}{(1-p i)}
$$

Onde:

- $\quad$ pi = taxa de substituição (peso) original do critério i;

- $\quad$ pi ' = taxa de substituição (peso) modificada do critério i;

- pn = taxa de substituição (peso) original do critério $n$;

- $\quad \mathrm{pn}^{\prime}=$ taxa de substituição (peso) modificada do critério $\mathrm{n}$.

Para a efetivação da análise de sensibilidade do modelo, a variação das taxas de substituição dos critérios sugerida é de $10 \%$ para mais e para menos. Consequentemente, se não for constatada a ocorrência de uma variação significativa na avaliação global após a aplicação das variações nos pesos dos critérios, o modelo pode ser considerado robusto (ou confiável).

Após a realização da análise de sensibilidade, com o incremento de $10 \%$ e redução de $10 \%$ na taxa de substituição (peso) de cada critério (PVF) e, em cada caso, recalculou-se a avaliação global e constatou-se que o modelo de avaliação desenvolvido é robusto, haja vista que não houve modificação significativa nas avaliações globais recalculadas. 


\section{Considerações Finais}

De acordo com os resultados obtidos, a gestão colaborativa dos grupos musicais independentes de Brasília é crítica e insatisfatória, haja vista que a avaliação global foi auferida com a nota $\mathbf{4 , 1 3}$, em uma escala de 0 a 10, demonstrando a ausência de profissionalismo na gestão de tais grupos.

Para a apuração da avaliação, foram considerados cinco critérios: Gestão da produção, Gestão organizacional, Divulgação, e Gestão de vendas. Cada critério constituiu-se em um ponto de vista fundamental que, por sua vez, foi desmembrado em pontos de vistas elementares e subelementares (subcritérios).

O PVF 1, que diz respeito à gestão da produção, obteve uma nota de 5,58, considerada pouco satisfatória, apesar de ter sido a maior nota alcançada dentre os critérios avaliados. A produção musical é o item de maior peso, representando $35 \%$ em relação a avaliação global, pois trata-se da principal atividade dos grupos musicais. O aspecto mais crítico dentro critério gestão da produção como um todo foi a produção de shows, representando a maior dificuldade dos grupos independentes de Brasília.

Já o PVF 2, que avaliou a gestão organizacional dos grupos, atingiu uma pontuação de 3,97, considerada negativa. Tal nota evidencia a baixa preocupação com relação à gestão financeira, gestão de recursos e planejamento, atividades que, se exercidas com maior atenção e esmero, podem garantir maior segurança ao grupo e melhor integração entre os envolvidos na produção musical. Ênfase deve ser dada à gestão dos recursos disponíveis dos grupos.

Quanto ao PVF 3, no qual avaliou-se a divulgação dos grupos, a nota obtida foi de 2,73, a mais baixa entre os critérios avaliados. Isso demonstra o baixo alcance comercial e de público dentre os grupos musicais independentes de Brasília, além da dificuldade de promover os seus trabalhos utilizando veículos de comunicação e divulgação tradicionais. Dessa forma, esses grupos precisam voltar-se para os meios digitais, como redes sociais, blogs, entre outros, de forma a direcionar suas divulgações para públicos específicos.

O PVF 4, que se refere à comunicação, obteve a pontuação de 4,20, o que reflete a insatisfação dos participantes em relação à comunicação interna, externa e à rede de contatos (networking) dos grupos musicais. Este é um item que gera grande preocupação, pois a comunicação é considerada como um dos pilares para o funcionamento de atividades praticadas com base na colaboração e no trabalho em equipe.

Por fim, o PFV 5, relacionado à gestão de vendas, obteve a nota 2,88. Essa nota retrata a dificuldade em gerar retorno financeiro através da venda de shows, de conteúdo físico e de conteúdo digital. Neste item, destaca-se que a venda de shows é um dos principais focos dos grupos musicais independentes, pois é considerada a principal fonte de renda. Por tanto, carece de maior atenção e maior desenvolvimento, para assim, trazer resultados positivos.

A baixa pontuação obtida foi recebida com surpresa para os autores do estudo, tendo ficado bem abaixo do esperado, visto que esses grupos dependem das práticas colaborativas e do trabalho em equipe para desenvolverem seus projetos e alcançarem seus principais objetivos. No entanto, apesar dos resultados não refletirem a expectativa inicial, entende-se que os grupos musicais independentes se apoiam sobre um grande esforço para conciliarem as diversas atividades que precisam desempenhar para produzirem, distribuírem e apresentarem seus produtos ao público. O que muitas vezes é feito unicamente por prazer, visto que o retorno financeiro que permita a autossustentação desses grupos não é o objetivo maior.

Vale ressaltar que muitos desses artistas precisam dividir o seu tempo entre a música e outras atividades profissionais, pois somente assim conseguem captar recursos para investirem em equipamentos e na produção musical. Outro fator que poderia ocasionar uma melhoria neste cenário é o investimento, por parte do Estado, em segmentos culturais independentes, de forma a impulsionar a revelação de novos artistas e oferecer maiores oportunidades para que consigam sobreviver fazendo aquilo que realmente gostam. 
Como proposta de melhoria para esses pontos, sugere-se que os grupos musicais independentes de Brasília despendam mais atenção aos processos que envolvem o gerenciamento e a organização de suas diversas atividades, trabalhando em conjunto, e colaborativamente, para garantir maior eficiência em suas cadeias produtivas. A organização, a comunicação, o planejamento, entre outras atividades aqui avaliadas, são tão importantes quanto a produção musical em si, pois trazem maior segurança ao grupo e garantem a sua soberania no cenário musical independente.

Como proposta de trabalhos futuros, sugere-se aplicar esse estudo de forma periódica, no mínimo a cada três anos, objetivando verificar se as melhorias sugeridas foram implementadas e se surtiram o efeito desejado. Adicionalmente, sugere-se a ampliação de estudo semelhantes em outros Estados do País fins obter um panorama abrangente a respeito da gestão colaborativa de grupos musicais independentes, em nível nacional.

\section{Referências}

Almeida, L. B., \& Moura, A. D. (2005). Avaliação da estratégia de desverticalização da cadeia moveleira de Ubá (MG) e região sob o enfoque dos modelos de decisão de fazer versus comprar. Congresso da Sociedade Brasileira de Economia e Sociologia Rural. Ribeirão Preto.

Almeida, M. E. (2005). O relacionamento entre parceiros na gestão de projetos de educação a distância: desafios e perspectivas de uma ação transdisciplinar. Congresso Mundial de Transdisciplinaridade. Vitória.

Amato Neto, J. (1994). Vertical desintegration/outsourcing and the subcontracting relations in the Brazilian automobile industry. Gestão \& Produção. 1(1), 2950 .

Amato Neto, J. (1995). Reestruturação industrial, terceirização e redes de subcontratação. Revista de Administração de Empresas. 35 (2), 33-42.

Anderson, C. (2006). A cauda longa: do mercado de massa ao mercado de nicho. São Paulo: Campus.

Antunes, A. T. (2012). Gestão colaborativa na cadeia de suprimentos: um estudo em cooperativas agrícolas. Dissertação de Mestrado em Administração, Faculdade de Gestão de Negócios, Universidade Metodista de Piracicaba, São Paulo.

Aquino, R. F. (2015). Práticas colaborativas e redes de aprendizagem em projetos artístico-educativos: um estudo de caso em Salvador. Anais do Colóquio Internacional Educação e Contemporaneidade. 09, 1-9. São Cristóvão-SE.

Bana e Costa, C. A. (1995). Uma nova abordagem ao problema da construção de uma função de valor cardinal: Macbeth. Investigação Operacional. 15, 15-35.

Beinat, E. (1995). Multiattribute value functions for environmental management. Amsterdam, Paises Baixos: Thesis.

Burgos, A., \& Mertens, F. (2016). As redes de colaboração no turismo de base comunitária: implicações para a gestão participativa. TMStudies. 12(2), 18-27. Fonte: http://www.scielo.mec.pt/scielo.php?script=sci_arttext\&pid=S2182-84582016000200003\&lng=pt\&nrm=iso

Búrigo, C. C., Cerny, R. Z., \& Teixeira, G. G. (2016). A gestão colaborativa no processo formativo da EAD. Revista Gestão Universitária na América Latina GUAL, 9(1), 165-176. https://doi.org/10.5007/1983-4535.2016v9n1p165

Camarinha-Matos, L. M., Afsarmanesh, H., Galeano, N., \& Molina, A. (2009). Collaborative networked organizations - Concepts and practice in manufacturing enterprises. 57, 46-60. https://doi.org/10.1016/j.cie.2008.11.024

Cogo, A. L. (2006). Cooperação versus colaboração: conceitos para o ensino de enfermagem em ambiente virtual. Revista Brasileira de Enfermagem. 59(5), 680-683.

Costa, M. S. (2017). Outsourcing in Brazil: old dilemmas and the need for a more including order. Cadernos EBAPE.BR, 15(1), 115-131. https://doi.org/10.1590/1679-395137235

Marchi, L. (2008). Indústria fonográfica e a nova produção independente: o futuro da música brasileira? Comunicação, Mídia e Consumo, 3(7), 167-182. https://doi.org/10.18568/1983-7070.37167-182\%y

Dias Tosta, M. (2000). Os donos da voz: indústria fonográfica brasileira e mundialização da cultura. São Paulo: Fapesp.

Ensslin, L., Montibeller Neto, G., \& Noronha, S. M. (2001). Apoio à decisão: metodologias para estruturação de problemas e avaliação multicritério de alternativas. Florianópolis: Insular.

Ferreira, A. O. de M., Silvino, Z. R., Balbino, C. M., Izu, M., Souza, C. J. de, \& Matias, D. de O. (2020). Multicriteria model for the quality control of geriatric diapers for hospital use. Research, Society and Development, 9(7), e753974835. https://doi.org/10.33448/rsd-v9i7.4835

Fleury, P. F. (2003). Supply chain management: conceitos, oportunidades e desafios da implementação. Centro de Estudos em Logística-UFRJ, Rio de Janeiro: UFRJ.

Galleta, T. P. (2014). Para além das grandes gravadoras: percursos históricos, imaginários e práticas do "independente" no Brasil. Música Popular em Revista. 3(1), 54-79. https://doi.org/10.20396/muspop.v3i1.12950. 
Gohn, D. (2008) Aspectos tecnológicos da experiência musical. Revista Música Hodie. 7(2), 11-28.

Gomes, L. C. \& Kliemann Neto, F. J. (2015). Métodos colaborativos na gestão de cadeias de suprimentos: desafios de implementação. Revista de Administração de Empresas. 55(5), 563-577.

Gomes, L. F. A. M. (2007). Teoria da decisão. São Paulo: Cengage Learning.

Gomes, R. M. (2016). Audio quality x accessibility: how digital technology changed the way we listen and consume popular music. Revista Vórtex, 4(2), 1-14.

Herschmann, M (2010). Indústria da Música em transição. São Paulo: Estação das Letras e Cores.

Hracs, B. J. \& Leslie, D. (2014). Aesthetic labour in creative industries: the case of independent musicians in Toronto, Canada. Área, 46(1), 66-73. https://doi.org/10.1111/area.12062

Hracs, B. J. (2012). A creative industry in transition: the rise of digitally driven independent music production. Growth and Change, 43(3), 442-461.

IFPI - International Federation of the Phonographic Industry. (2019). Global music report: state of the industry. London: IFPI.

Keeney, R. (1996). Value focused-thinking: a path to creative decision-making., Cambridge: Harvard University Press.

Landry, M. (1995). A note on the concept of 'problem'. Organization Studies, 16, 2315-2343.

Leite, M. C. B. (2011). Avaliação da estrutura de governança da rede de políticas públicas do setor saneamento por meio da utilização de métodos multicritérios de apoio à tomada de decisão. Dissertação de Mestrado em Administração. Faculdade de Economia, Administração, Contabilidade e Gestão de Políticas Públicas, Universidade de Brasília, Brasília.

Martinho, M. H. (2018). A colaboração como oportunidade de desenvolvimento profissional. Revista Thema. 15(1), 1-44.

Min, S., Roath, A. S., Daugherty, P. J., Genchev, S. E., Chen, H., Arndt, A. D., \& Richey, R. G. (2005). Supply chain collaboration: what's happening? The International Journal of Logistics Management. 16(2), 237-256. https://doi.org/10.1108/09574090510634539

Moreira, F. R., da Silva Filho, D., Nze, G. D. A., Sousa Júnior, R. T., Nunes, R. R. (2021). Evaluating the Performance of NIST's Framework Cybersecurity Controls Trough a Constructivist Multicriteria Methodology. IEEE Access. 9, 129605-129618. https://doi.org/10.1109/ACCESS.2021.3113178

Nakano, D. N. (2010) A produção independente e a desverticalização da cadeia produtiva da música. Gestão \& Produção. 17(3), 627-638, https://doi.org/10.1590/s0104-530x2010000300015

Pacheco Junior, J. M. C. \& Gomes, R. (2016). Tomada de decisão e alta administração: a implantação de projetos de mudanças de gestão da clínica em hospitais do SUS. Ciência e Saúde Coletiva. 21(8), 2485-2496. https://doi.org/10.1590/1413-81232015218.20012015

Quirino, M. G. (2002). Incorporação das Relações de Subordinação na Matriz de Ordenação - Roberts em MCDA quando os Axiomas de Assimetria e de Transitividade Negativa são Violados. Tese de Doutorado em Engenharia de Produção. Universidade Federal de Santa Catarina, Florianópolis.

Rodrigues, D. M., \& Sellitto, M. A. (2008). Práticas logísticas colaborativas: o caso de uma cadeia de suprimentos da indústria automobilística. Revista de Administração. 43(1), 97-111. https://doi.org/10.1590/S0080-21072008000100008

Romero, A. P. R.C. (2004). Desdobramentos e tendências atuais da reestruturação industrial. Rio de Janeiro, 2004. Dissertação de Mestrado (Engenharia Industrial). Industrial, Pontifícia Universidade Católica do Rio de Janeiro, Rio de Janeiro.

Roy, B. (1996). Multicriteria methodology for decision aiding. Boston: Kluwer Academic Publishers.

Roy, B. \& Vanderpooten (1996). D. The European School of MCDA: Emergences, Basic Features raid Current Works. Journal of Multicriteria Decision Analysis. 5, pp. 23-38.

Almeida, M. E. (2005). O relacionamento entre parceiros na gestão de projetos de educação a distância: desafios e perspectivas de uma ação transdisciplinar. Congresso Mundial de Transdisciplinaridade. Vitória.

Saldanha, L.V. (2013). Música \& mídia - a música popular brasileira na indústria cultural. Encontro Nacional de História da Mídia. 9. Ouro Preto.

Silveira Júnior, A., Nunes, R. R. \& Rodrigues, E. C. C. (2021). Evaluation of operating conditions of cargo transportation by cabotage in Brazil: a multicriteria approach from the shipowners' point of view. Research, Society and Development. 10(8), e55410817693. https://doi.org/10.33448/rsd-v10i8.17693

Silveira Jr., A. (2018). Cabotagem brasileira: uma abordagem multicritério. Curitiba: Appris.

Siqueira, C. O., Ganga, G. M. D. \& Santa-Eulalia, L. A. (2015). A visão de um fornecedor-chave sobre a colaboração com a montadora. Gestão \& Produção. 22(4), 902-919. https://doi.org/10.1590/0104-530X1482-14.

Souza, F. A. S. \& Lemos, A. H. C. (2016). Terceirização e resistência no Brasil: o Projeto de Lei n. $4.330 / 04$ e a ação dos atores coletivos. Cadernos EBAPE.BR. 14(4), 1035-1053

Stefani, C. E., Duduchi, M. \& Azevedo, M. M. (2020). Análise multicritério para seleção de membros de equipes para projetos de software. Research, Society and Development. 9(11), e2609119693. https://doi.org/10.33448/rsd-v9i11.9693

Vicente, E. (2006). A vez dos independentes(?): um olhar sobre a produção musical independente do país. E-Compós, 7. https://doi.org/10.30962/ec.100 
Research, Society and Development, v. 10, n. 13, e563101321641, 2021

Vitorino Filho, V. A., Pires, S. R. I., Argoud, A. R. T. T. \& Simon, A. T. (2016). Gestão colaborativa em cadeias de suprimentos: um estudo bibliométrico. Gestão \& Regionalidade, 32(96), 111-134. https://doi.org/10.13037/gr.vol32n96.3527.

Vogel, H. L. (2011). Entertaiment industry economics: a guide for financial analysis. Cambridge: Cambridge University Press.

Wagner, H. M. (1986). Pesquisa operacional. Rio de Janeiro: Prentice-Hall. 